\title{
RESPON SISWA TERHADAP MODUL PEMBELAJARAN BERBASIS SAVI (SOMATIC, AUDITORY, VISUALITATION, INTELLEGENCY) PADA MATERI EKOSISTEM DI SMAN 1 PAPAR
}

\author{
Valentina Nunung Dea Ristanti, Mumun Nurmilawati, Tutut Indah Sulistiyowati \\ Program Studi Pendidikan Biologi \\ FKIP Universitas Nusantara PGRI Kediri \\ Jl. KH. Achmad Dahlan No. 76 Kediri \\ valendea1@gmail.com
}

\begin{abstract}
ABSTRAK
Tujuan dari penelitian ini adalah untuk mengetahui respon siswa terhadap modul pembelajaran berbasis SAVI (Somatic, Auditory, Visualitation, Intellegency) pada materi ekosistem. Penelitian ini menggunakan model pengembangan ADDIE, dengan uji coba skala kecil. Instrumen penelitian menggunakan angket respon siswa. Hasil respon 10 siswa uji coba kelompok kecil terhadap modul ekosistem adalah sebesar $81,9 \%$ dengan kriteria sangat positif sehingga modul dapat digunakan dalam pembelajaran biologi pada materi ekosistem.
\end{abstract}

Kata kunci: respon siswa, modul pembelajaran, SAVI.

\section{PENDAHULUAN}

Modul pembelajaran adalah materi pelajaran yang tersusun secara tertulis agar siswa dapat memahami materi secara mandiri untuk meminimalkan bantuan dari orang lain [1]. Modul memiliki kelebihan dibandingkan bahan ajar yang lainnya. Kelebihan modul dapat dilihat dari kelengkapan isinya. Modul berisi suatu langkah belajar yang utuh. Menurut Madya [2] modul dilengkapi dengan soal-soal latihan, kunci jawaban beserta petunjuk penilaian. Soal-soal latihan tersebut dapat digunakan untuk mengukur tingkat penguasaan materi siswa.

Berdasarkan hasil observasi yang telah dilakukan, sumber belajar yang digunakan oleh siswa kelas X MIA 1 di SMAN 1 Papar adalah hanya menggunakan buku paket dari pemerintah saja. Satu bangku diberi satu buku. Sehingga salah satu siswa yang tidak membawa buku tersebut tidak dapat belajar mandiri di rumah. Keterbatasan buku paket tersebut menyebabkan siswa kurang memahami materi pelajaran yang di sampaikan guru di kelas, khususnya pada materi ekosistem. Selain itu, cara guru mengajar pada materi ekosistem adalah dengan mengajak siswa melakukan pengamatan langsung ke alam. Meskipun demikian, banyak siswa mengalami kebingungan karena belum adanya buku panduan yang disusun secara sistematis yang dapat digunakan siswa sebagai acuan saat melakukan pengamatan. Sedangkan untuk memahami materi ekosistem perlu adanya pengamatan langsung di alam yang didukung dengan sebuah buku panduan. Nilai rata-rata siswa pada materi ekosistem dibawah standart Kriteria Ketuntasan Minimal yang telah ditetapkan sekolah. Kriteria Ketuntasan Minimal di SMAN 1 Papar adalah 75.

Selain faktor bahan ajar, pemilihan model pembelajaran yang tepat juga dapat mempengaruhi proses pemahaman siswa. Hal tersebut pernah disampaikan oleh Novitayani [3], bahwa jika susunan modul disertai dengan model pembelajaran yang tepat dan menarik, maka siswa akan termotivasi dan memiliki perhatian yang lebih untuk belajar. Salah satu model pembelajaran yang dapat digunakan adalah SAVI( Somatic, Auditory, Visual, Intellegency). Menurut Meier [4] dan Suherman [5] model pembelajaran SAVI menekankan bahwa belajar haruslah memanfaatkan semua alat indra yang dimiliki siswa, belajar dapat optimal jika keempat unsur SAVI ada di dalam satu peristiwa pembelajaran. Penelitian ini bertujuan untuk mengetahui respon siswa terhadap modul pembelajaran berbasis SAVI pada materi ekosistem di kelas X MIA 1 SMAN 1 Papar.

\section{METODE}

Jenis penelitian ini adalah penelitian dan pengembangan dengan menggunakan model pengembangan ADDIE (Analysis, Design, Development, Implementation, and Evaluation)[6]. 


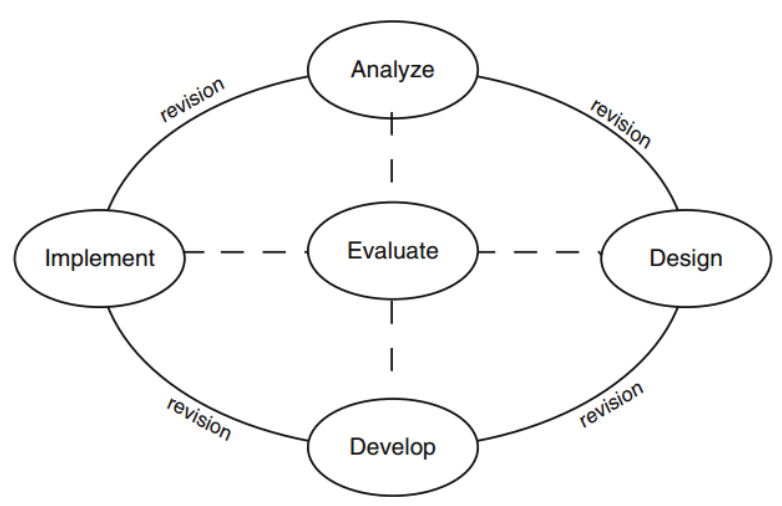

Gambar 1. Konsep model pengembangan ADDIE.

Instrumen penelitian menggunakan angket respon siswa yaitu untuk mengetahui respon siswa terhadap modul ekosistem yang digunakan saat pembelajaran. Desain uji coba produk dalam penelitian pengembangan ini menggunakan desain pre-eksperimen dan sasaran uji coba modul adalah kelompok kecil yang terdiri dari 10 siswa kelas X MIA 1 SMAN 1 Papar.

Teknik analisis data menggunakan teknik analisis data deskriptif kuantitatif. Teknik ini digunakan untuk mengetahui respon siswa setelah diberikan modul. Langkah-langkah analisis data angket respon siswa, sebagai berikut:

1) Membuat skor penilaian menggunakan skala likert.

Skor penilaian pada angket respon siswa yaitu:

Poin $4=$ Sangat Setuju Sekali

Poin $3=$ Setuju

Poin $2=$ Kurang Setuju

Poin $1=$ Tidak Setuju

2) Menghitung banyak siswa yang memilih setiap pilihan jawaban pada masing-masing item pernyataan.

3) Menghitung nilai respon siswa untuk setiap kategori jawaban siswa dengan cara mengalikan banyaknya siswa yang memilih jawaban dengan skor pilihan jawaban tersebut.

4) Menghitung total nilai respon siswa setiap item pernyataan. Kemudian mencari persentase nilai respon siswa pada setiap item pernyataan dengan menggunakan rumus dari Sudjana [7]:

$\% \mathrm{NRS}=\frac{\sum N R S}{\text { NRS Maksimum }} \times 100 \%$

5) Menentukan kategori untuk nilai respon siswa menggunakan ketentuan berikut [8]:

Tabel 1. Kriteria Presentase Respon Siswa

\begin{tabular}{ll}
\hline Interval & Kriteria \\
\hline $81,25<\mathrm{NRS} \leq 100 \%$ & Sangat Positif \\
\hline $62,5<\mathrm{NRS} \leq 81,25$ & Positif \\
\hline $43,75<\mathrm{NRS} \leq 62,5$ & Kurang Positif \\
\hline $25<\mathrm{NRS} \leq 43,75$ & Tidak Positif \\
\hline
\end{tabular}

\section{HASIL DAN PEMBAHASAN}

Angket respon siswa yang digunakan dalam penelitian ini memuat 10 aspek penilaian. Semua aspek yang dinilai dalam modul ini menunjukkan kriteria positif dan sangat positif dengan perolehan skor rerata sebesar $81,9 \%$, skor tersebut menunjuk pada kriteria sangat positif sehingga modul ini dapat dikatakan sangat positif untuk diterapkan dalam pembelajaran biologi pada materi ekosistem. Respon tertinggi siswa terdapat pada aspek uraian materi yaitu sebesar $90 \%$ dengan 
kriteria sangat positif. Hasil rekapitulasi respon siswa terhadap modul ditunjukkan pada tabel 2 di bawah ini.

Tabel 2. Hasil respon siswa terhadap modul

\begin{tabular}{llll}
\hline No. & Aspek yang dinilai & $\mathbf{P ( \% )}$ & Kriteria \\
\hline 1. & Cover & 77,5 & Positif \\
\hline 2. & Daftar Isi & 77,5 & Positif \\
\hline 3. & Pendahuluan & 83,7 & Sangat positif \\
\hline 4. & Petunjuk Penggunaan Modul Bagi Siswa & 80 & Positif \\
\hline 5. & Tujuan Pembelajaran & 87,5 & Sangat positif \\
\hline 6. & Uraian Materi & 90 & Sangat positif \\
\hline 7. & Kegiatan Belajar Siswa & 81,2 & Positif \\
\hline 8. & Soal Latihan & 77,5 & Positif \\
\hline 9. & Umpan Balik & 82,5 & Sangat positif \\
\hline 10. & Rangkuman & 82,5 & Sangat positif \\
\hline & Rerata & $\mathbf{8 1 , 9}$ & Sangat positif \\
\hline
\end{tabular}

\section{SIMPULAN}

Respon positif siswa terhadap modul ekosistem adalah sebesar $81,9 \%$, sehingga modul ini dapat digunakan dalam pembelajaran biologi pada materi ekosistem.

\section{DAFTAR RUJUKAN}

[1]. LKKP UNHAS. 2015. Bahan Ajar, Buku Ajar, Modul, dan Panduan Praktik. Makassar: UNHAS.

[2]. Madya, D., Widyaiswara. 2013. Pengembangan Bahan Ajar Modul (online). Tersedia: http:www.vedmalang.com, diunduh 23 Mei 2018.

[3]. Novitayani, L., Sukarmin., Sukarmi. 2016. Pengembangan Modul Fisika Berbasis Somatic, Auditory, Visual, Intellectual (SAVI) Untuk Meningkatkan Kreativitas Belajar Siswa Kelas X SMA/MA Dengan Topik Kalor Dan Perpindahannya. Jurnal Inkuiri, 5 (2): 20-29.

[4]. Meier, Dave. 2000. The Accelerated Learning Handbook. New York: McGrawHill.

[5]. Suherman, Erman. 2008. Model Belajar Dan Pembelajaran Berorientasi Kompetensi Siswa. Jurnal Pendidikan dan Budaya, 5 (2): 1-31.

[6]. Branch, R. M. 2009. Instructional Design: The ADDIE Approach. Departement of Educational Psychology and Instructional Technology. University of Georgia.

[7]. Sudjana, Nana. 2011. Penilaian Hasil dan Proses Belajar Mengajar. Bandung: Rosda Karya.

[8]. Widyastuti, T. Ari. 2018. Pengembangan Modul Berbasis Inkuiri Terbimbing Pada Materi Organisasi Kehidupan Untuk Siswa Kelas VII di SMPN 2 Papar. Skripsi. Tidak dipublikasikan. Kediri: UN PGRI Kediri. 